Research Article

\title{
Control of the Chamber in Extra-Thick Coal Seam Based on Fracture Characteristics of Coal Rock and Mass
}

\author{
Yang Tai, ${ }^{1,2}$ Guozhi Lu $\mathbb{D}^{1},{ }^{1}$ Hongchun Xia, ${ }^{3}$ Jinrong Liu, ${ }^{4}$ and Yanqun Zhang ${ }^{4}$ \\ ${ }^{1}$ College Engery and Mining Engineering, Shandong University of Science and Technology, Qingdao 266590, China \\ ${ }^{2}$ School of Mines, China University of Mining and Technology, Xuzhou 221116, China \\ ${ }^{3}$ College of Architectural Engineering, Dalian University, Liaoning, Dalian 116622, China \\ ${ }^{4}$ Datong Coal Mine Group Co. Ltd., Datong 037000, China \\ Correspondence should be addressed to Guozhi Lu; skdguozhilu@163.com
}

Received 21 September 2019; Revised 1 February 2020; Accepted 20 May 2020; Published 28 June 2020

Academic Editor: Chao Wu

Copyright ( 92020 Yang Tai et al. This is an open access article distributed under the Creative Commons Attribution License, which permits unrestricted use, distribution, and reproduction in any medium, provided the original work is properly cited.

\begin{abstract}
As the development characteristics of cracks of the chamber are closely related to the bolt and cable anchoring parameters, the original rock stress of the surrounding rock, and fracture degree, this paper proposes the control method for chamber in extrathick coal seam by the crack development characteristics. Based on the numerical model analysis, the chamber generates a large amount of shear cracks. Then, these cracks further extend and expand. When the cracks penetrate each other, the chamber bearing capacity decreases sharply, and the corresponding displacement also increases significantly. Based on the above rules, a chamber control method by high-strength anchor bolts and grouting reinforcement is proposed to improve the rock shear strength. By optimizing the anchor bolt parameters and grouting parameters, such as spacing, length, and the grouting pressure, the cracks are significantly reduced and the cracks are prevented from penetrating. Finally, an industrial test was conducted in the chamber at Datong Coal Group, and the chamber deformation was well controlled.
\end{abstract}

\section{Introduction}

With the development of the coal industry, several largescale coal production bases have successively appeared in China, forming many modern high-yield and high-efficiency mines with a capacity of 10 million tons [1]. For example, the Datong Coal Group can produce more than 0.13 billion tons coal in one year, while the output of the mines with a capacity of 10 million tons accounts for about 70\% [2]. The main coal seam of those modernized mines exploits generally thick and extra-thick coal seams $[3,4]$. Due to the large coal output of these mines, the sections of underground electromechanical chambers, gangue washing chambers, and assembly chambers are usually above $70 \mathrm{~m}^{2}$ [5]. When the coal seam is thick and the strength is high, the chamber is preferentially put in the coal seam. The support theory for chambers in such extra-thick coal seams mainly includes the loosened ring theory, reinforcement arch theory, and prestressed support theory. The loosened ring theory generally emphasizes that the anchor ends of the anchor bolt are arranged outside the loosened ring, which provides a force point for the pretightening force application [6]. This theory provides theoretical guidance for the design of lengths of anchor bolt but does not consider some support parameters such as pretightening force (PTF) and anchor bolt spacing [7]. In addition, the loosened ring of the chamber is usually replaced by a plastic zone. As shown in Figure 1(a), the chamber in coal seams has a large span and height, and the strength of the coal seam is lower than that of the rock. Therefore, the plastic zone is generally large. Although the anchoring end of the anchor cable can generally be placed in an intact zone outside the loosen ring, the loosen ring thickness is often greater than the bolt length [8]. Therefore, according to the loosen ring theory, it is impossible to explain the support effect for the bolt in the fracture zone of a chamber in the extra-thick coal seam. At the same time, it cannot provide a theoretical basis for the anchor bolt spacing. 


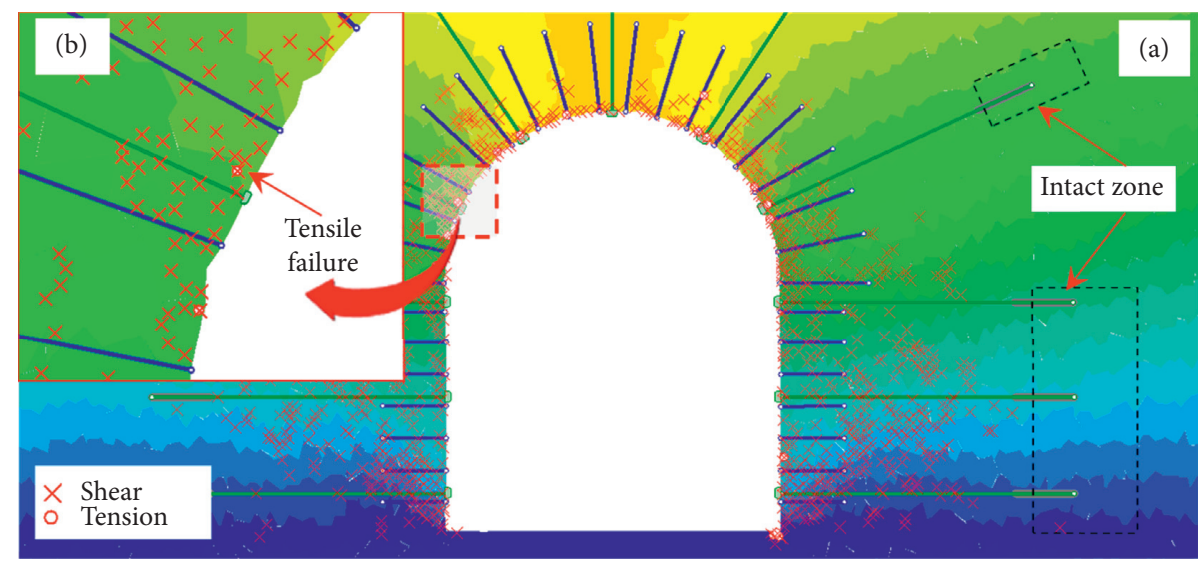

Figure 1: Plasticity characteristics of the chamber.

Since the tensile strength of coal is lower than its shear strength, tensile damage is formed on the surface of the chamber, as shown in Figure 1(b). Based on this feature, the reinforcement arch theory and prestressed support theory are proposed. The reinforcement arch theory and prestressed support theory optimize the anchor bolt support parameters to make the formation of compressive stress layer as much as possible on the surface of roadways or the chambers [9]. Both of them can provide basis for the support parameters, such as anchor bolt spacing, length, and pretightening force of the chamber, but they ignore the original rock stress and fracture degree of the chamber.

After the formation of chambers, its deformation and failure are mainly the process of initiation, expansion, and penetration of cracks [10-12]. The chamber will inevitably produce many cracks, as shown in Figure 2. The crack development is directly connected with the anchor bolt support parameters, and it is also closely related to the original rock stress and the crack development degree of the chamber. Therefore, this paper proposes the control method of the chamber of extra-thick coal seam based on the fracture development characteristics. The research of this subject can provide the basis for the selection of support parameters for anchor bolt and cable. At the same time, it can consider the original rock stress and fracture degree of the surrounding rock of the chamber.

After introducing the chamber at Datong Coal Group, this paper uses numerical simulation to establish a numerical model for the development of cracks in the chamber, which is used to reveal the relationship between the fracture development characteristics and the chamber deformation. On this basis, the corresponding control technology of the chamber is proposed, and finally the industrial test is conducted in the chamber at Datong Coal Group.

\section{Background}

Tashan Coal Mine is the biggest mine in the Datong Coal Group. It is currently mining carboniferous coal seams, and its annual production of coal per working face is 15 million tons. Due to the large coal output, the mine has high requirements for the section of the chamber. According to the requirements of the electromechanical equipment for the installation space, as shown in Figure 3(a), the chamber size is $9.5 \mathrm{~m} \times 11.85 \mathrm{~m}$. Due to the high strength of the \#3-5 coal seam, the chamber is put in the \#3-5 coal seam. From the drill core near the chamber, the buried depth of the coal seam is $528.5 \mathrm{~m}$ and its thickness is $18.1 \mathrm{~m}$. The floor and roof are all mudstone, and the rock stratum is shown in Figure 3(b).

\section{Constitutive Model of Surrounding Rock of the Chamber}

The choice of the constitutive model for rock in the numerical model is crucial. This chapter first analyzes three typical constitutive models of the rock. Then based on the brittleness characteristic of coal rock mass, the appropriate constitutive model is chosen.

3.1. Constitutive Model of the Rock. In order to get the constitutive model for the rock, domestic and foreign scholars have given three typical constitutive models of rock based on a large number of compaction tests, as shown in Figure 4 [13]. When the rock reaches the peak stress, three different paths appear: Path (1): the ideal elastoplastic model, that is, the stress remains unchanged after the coal rock mass reaches the peak stress. Path (2): when the rock reaches the peak stress, the stress falls along a certain curve and decreases to a certain stress level. Path (3): after the rock reaches the peak stress, the stress suddenly drops to a certain level.

The stress-strain curve of the rock in the traditional numerical model often adopts Path (1), which considers the rock as an ideal elastoplastic model. However, a large number of experiments and engineering practices have shown that the rock shows a strain-softening phenomenon after reaching the peak, namely Path (2) and Path (3). When the brittleness of the rock is strong, the stress-strain relationship after peak is close to Path (3). The coal from Tashan Coal Mine has typical brittle characteristics, so this paper adopts the constitutive model of Path (3) [14]. 


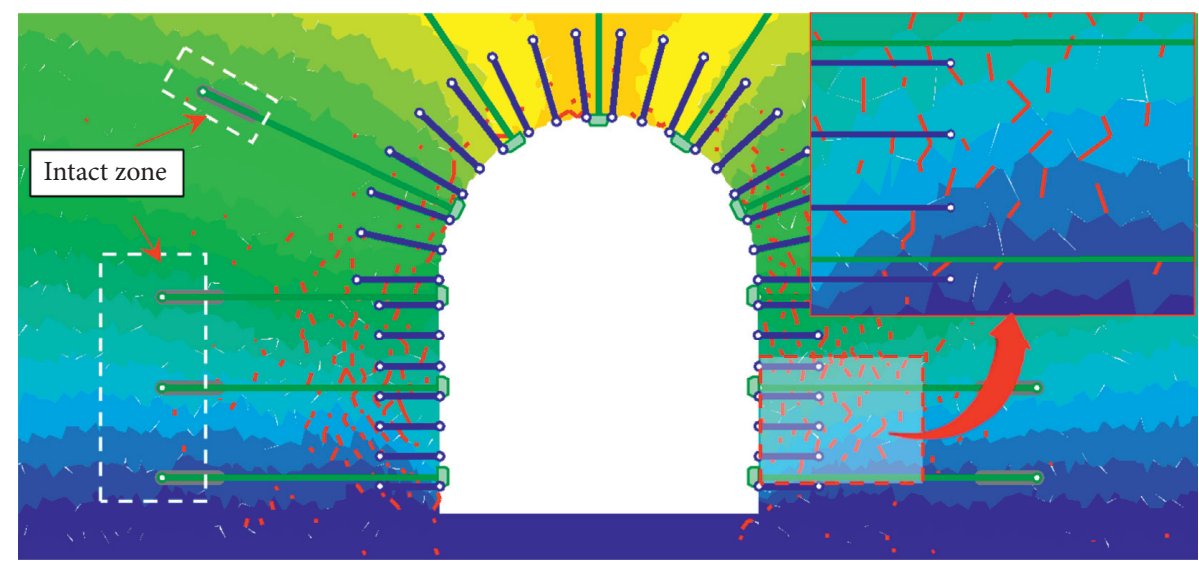

Figure 2: Crack development characteristics of the chamber.



(a)

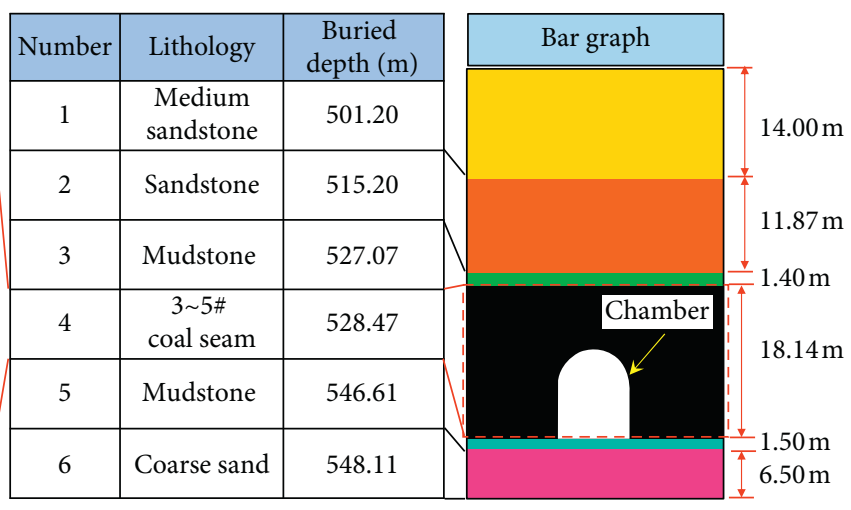

(b)

Figure 3: (a) Chamber size and (b) rock stratum bar graph.

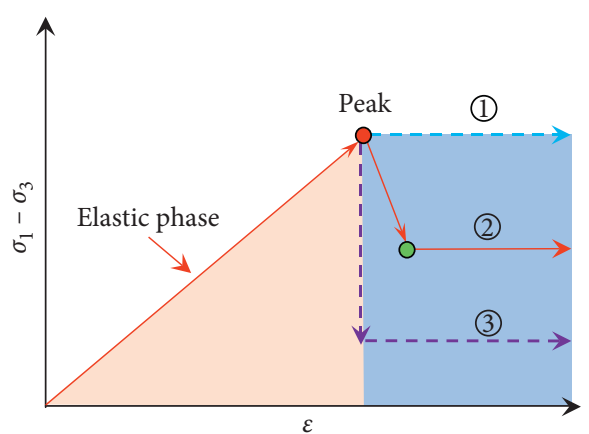

Figure 4: Typical constitutive model of coal rock mass.

\subsection{Strain-Softening Model Based on the Hoek-Brown} Criterion. In order to consider native joints or cracks in the chamber, the Hoek-Brown strength criterion is used in this paper. Its specific expression is as follows [15]:

$$
\sigma_{1}=\sigma_{3}+\sigma_{c}\left(m_{b} \frac{\sigma_{3}}{\sigma_{c i}}+s\right)^{a}
$$

where $\sigma_{3}$ and $\sigma_{1}$ are the third and first principal stresses at failure, respectively; $m_{\mathrm{b}}, s$, and $a$ are constants; $\sigma_{\mathrm{c}}$ is the uniaxial compressive strength. The expressions of $m_{\mathrm{b}}, s$, and $a$ are as follows [16]:

$$
\begin{aligned}
m_{b} & =m_{i} \exp \left(\frac{G S I-100}{28-14 D}\right), \\
s & =\exp \left(\frac{G S I-100}{9-3 D}\right), \\
a & =\frac{1}{2}+\frac{1}{6}\left(e^{-G S I / 15}-e^{-20 / 3}\right),
\end{aligned}
$$

where GSI is the geological strength index. The parameter $D$ is the "disturbance factor." $m_{\mathrm{i}}$ is the material constant for the intact rock.

The GSI, $m_{i}$, and $D$ values are the key parameters for calculating $m_{\mathrm{b}}, s$, and $a$; the RocData software is used to find the $m_{i}$ values for different lithologies.

The disturbance factor $D$ can be calculated from the following:

$$
D=2\left[1-(1-\lambda)^{2}\right]
$$


where $\lambda$ is the ratio of elastic wave velocity before and after excavation.

The GSI value is evaluated based on the rock structure and the weathering degree on the surface of rock. The accuracy of GSI evaluation depends mainly on the experience of geologists. In order to facilitate the use of the GSI system and improve its accuracy, Cai et al. [14] gave a method for quantifying the GSI value based on the rock mass $V_{\mathrm{b}}$ and the joint surface coefficient $J_{c}$. The specific equation is given as follows:

$$
\operatorname{GSI}\left(V_{b}, J_{c}\right)=\frac{26.5+8.79 \ln J_{c}+0.9 \ln V_{b}}{1+0.0151 \ln J_{c}-0.0253 V_{b}} .
$$

$V_{\mathrm{b}}$ and $J_{\mathrm{c}}$ in the above equation can be expressed as follows:

$$
\begin{gathered}
V_{b}=\frac{s_{1} s_{2} s_{3}}{\sin \gamma_{1} \sin \gamma_{2} \sin \gamma_{3}}, \\
J_{c}=\frac{J_{W} J_{S}}{J_{A}},
\end{gathered}
$$

where $s_{1}, s_{2}$, and $s_{3}$ are the joint spacing of the rock in three directions. $\gamma_{1}, \gamma_{2}$, and $\gamma_{3}$ are the joint angles of the joint faces in three directions of the rock block. $J_{W}, J_{S}$, and $J_{A}$ are macroscopic fluctuation coefficients, joint microsmooth coefficients, and joint alteration coefficients, respectively.

As shown in Figure 5, the joint spacing of the rock in three directions of the rock is obtained by field statistics.

For $J_{W}, J_{S}$, and $J_{A}$, the specific values are as follows:

The $J_{W}$ values are presented in Table 1. According to the joint macroscopic fluctuation of the rock in Tashan Coal Mine, the value here is 1.00 .

The $J_{\mathrm{s}}$ values are presented in Table 2. According to the joint smoothness of the rock in Tashan Coal Mine, the value here is 0.75 .

The $J_{\mathrm{A}}$ values are presented in Table 3 . According to the alternation of the rock in Tashan Coal Mine, the value here is 0.75 .

According to equations (4) (6), the GSI value is given. The values of $m_{\mathrm{b}}, s$, and $a$ can be calculated using the GSI, $m_{i}$, and $D$ values, as shown in Table 4 .

To simulate the strain-softening behavior of coal rock after peak stress, Cai et al. proposed a strain-softening model based on the Hoek-Brown strength criterion, which is embodied by the residual $G_{S I}$. After the peak stress, the strain-softening process of rock mass is simulated by reducing the initial GSI. The residual $G I_{r}$ value can be calculated from initial GSI value as follows [14]:

$$
G I_{r}=G S I \cdot e^{-0.134 G S I} \text {. }
$$

\section{Numerical Model for Crack Development in a Chamber}

4.1. Slip and Open Model for Crack Development. Many cracks will occur during the destruction process of the chamber. In order to simulate the crack development, the

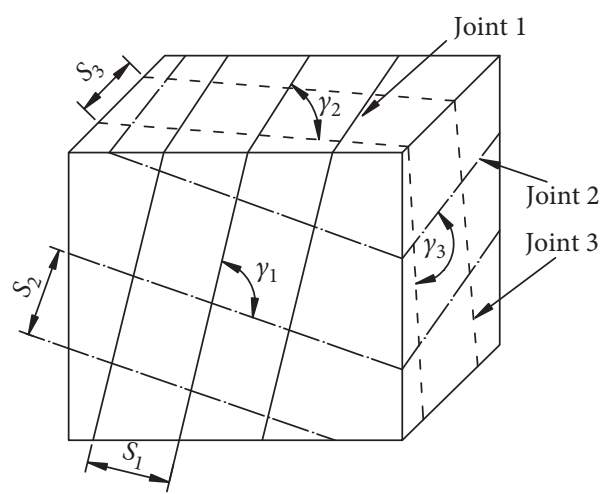

FIGURE 5: Sketch map of rock mass delimited by three joint sets.

chamber is divided into the Voronoi elements. The slip and open model between the Voronoi elements are shown in Figure 6 [17]. [18]:

The equations for $K_{n}$ and $K_{s}$ in the model are as follows

$$
\begin{aligned}
& K_{n}=10\left[\frac{K+(4 / 3) G}{\Delta Z_{\min }}\right], \\
& K_{s}=0.4 K_{n},
\end{aligned}
$$

where $\Delta \mathrm{Z}_{\text {min }}$ is the smallest width of the zone. $G$ is the shear modulus and $K$ is the bulk modulus of the rock. They can be expressed as follows [19]:

$$
\begin{aligned}
& K=\frac{E}{3(1-2 \mu)}, \\
& G=\frac{E}{2(1+\mu)},
\end{aligned}
$$

where $E$ is the elastic modulus and $\mu$ is Poisson's ratio, respectively. To further calibrate $K_{n}$ and $K_{s}$, the uniaxial compression is simulated to obtain the relationship of stress and strain, which is then adjusted with the test. After multiple adjustments, more accurate $K_{n}$ and $K_{s}$ are obtained.

4.2. Rock Strength Reduction. The chamber contains native cracks and joints. Therefore, the experimentally determined rock mass mechanical parameters are usually higher than those of the rock from the stope. Therefore, the strength of the rock in the laboratory is reduced by the RQD (rock quality designation) value in engineering, which can then be used as the mechanical parameter of the rock from the stope. The elastic modulus $E$ is from the laboratory rock, while the elastic modulus $E_{\mathrm{m}}$ is from the stope rock. They have the following relationship [20]:

$$
\frac{E_{m}}{E}=10^{0.0186 R Q D-1.91}
$$

The $\sigma_{\mathrm{cm}}$ is the uniaxial compressive strength from laboratory rock, while $\sigma_{\mathrm{cm}}$ is the uniaxial compressive strength from the stope. Similarly, $\sigma_{\mathrm{cm}} / \sigma_{\mathrm{c}}$ has the following relationship with $E_{\mathrm{m}} / E$ [21]: 
TABLE 1: Characterization and rating of joint macroscopic fluctuation coefficients $J_{\mathrm{w}}$.

\begin{tabular}{lcccc}
\hline Discontinuity & Strong fluctuation & Moderate fluctuation & Slightly fluctuation & No fluctuation \\
\hline 4.00 & 1.50 & 1.25 & 1.00 & 0.75 \\
\hline
\end{tabular}

TABLE 2: Characterization and rating of joint microsmooth coefficients $J_{s}$.

\begin{tabular}{lccccc}
\hline Very rough & Relatively rough & Slightly rough & Relatively smooth & Smooth & Very smooth \\
\hline 2.00 & 1.50 & 1.25 & 1.00 & 0.75 & 0.50 \\
\hline
\end{tabular}

TABLE 3: Characterization and rating of joint alteration factor $J_{\mathrm{A}}$.

\begin{tabular}{|c|c|c|}
\hline Classification of structural surface alteration properties & Description & $J_{\mathrm{A}}$ \\
\hline \multirow{5}{*}{$\begin{array}{l}\text { Local erosion and weathering exist on the structural } \\
\text { surface, and the wall is closely contacted }\end{array}$} & Structural surface closed, no filling & 0.75 \\
\hline & Fresh structural surface, no weathering & 1.00 \\
\hline & Slightly weathered structural surface, with color infection on the wall & 2.00 \\
\hline & The structure is intensively weathered with sand and silt on the wall & 3.00 \\
\hline & $\begin{array}{l}\text { The structural surface is altered and completely weathered, and the wall } \\
\text { surface is covered with clay, kaolin, and other alternates }\end{array}$ & 4.00 \\
\hline \multirow{4}{*}{$\begin{array}{l}\text { There are fillings between structural surfaces, and the wall } \\
\text { surface is partially closed or not contacted }\end{array}$} & $\begin{array}{l}\text { The structural planes are partially filled with sand and silt, and the walls } \\
\text { are partially closed }\end{array}$ & $4 \sim 8$ \\
\hline & $\begin{array}{c}\text { The structural planes are filled with hard cohesive materials such as } \\
\text { kaolin and clay, which are closely packed }\end{array}$ & $6 \sim 8$ \\
\hline & $\begin{array}{l}\text { The structural planes are filled with soft cohesive materials such as } \\
\text { ultra-consolidated clay, which are closely packed }\end{array}$ & $8 \sim 1$ \\
\hline & $\begin{array}{l}\text { The structural planes are filled with expansive clay, which is closely } \\
\text { filled }\end{array}$ & $10 \sim 18$ \\
\hline
\end{tabular}

TABLE 4: Mechanical parameters of the rock.

\begin{tabular}{lccccccccc}
\hline Lithology & Elastic modulus $E(\mathrm{GPa})$ & $\sigma_{\mathrm{c}}(\mathrm{MPa})$ & Poisson's ratio $\mu$ & $G S I$ & $m_{\mathrm{i}}$ & $D$ & $m_{\mathrm{b}}$ & $s$ \\
\hline Medium sand & 45.5 & 69.4 & 0.26 & 86 & 17 & 0 & 9.098 & 0.2111 & 0.500 \\
Sandstone & 54.2 & 78.2 & 0.32 & 89 & 21 & 0 & 14.178 & 0.2946 & 0.500 \\
Mudstone & 15.8 & 17.4 & 0.29 & 65 & 10 & 0 & 2.865 & 0.0205 & 0.500 \\
\#3-5 coal & 6.8 & 13.2 & 0.26 & 75 & 11 & 0.2 & 4.079 & 0.0510 & 0.501 \\
Mudstone & 15.2 & 7.2 & 0.31 & 63 & 12 & 0 & 3.201 & 0.0164 & 0.502 \\
Coarse sandstone & 35.1 & 75.6 & 0.25 & 89 & 20 & 0 & 13.503 & 0.2946 & 0.500 \\
\hline
\end{tabular}

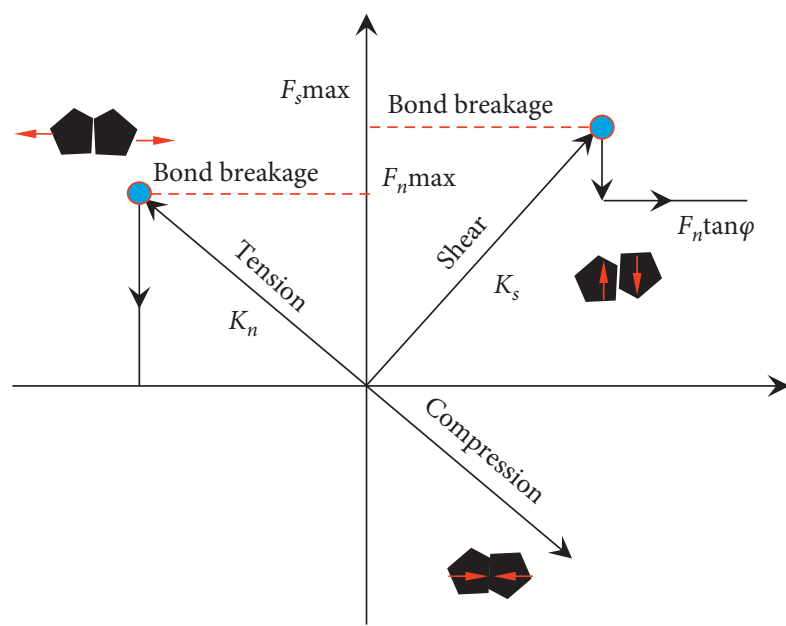

FIGURE 6: Slip and open model for crack development.

$$
\frac{\sigma_{c m}}{\sigma_{c}}=\left(\frac{E_{m}}{E}\right)^{q}
$$

where $q$ is a key parameter. According to reference [22], it is taken as 0.7. The uniaxial tensile strength $\sigma_{\mathrm{tm}}$ is about 0.1 times the uniaxial compressive strength $\sigma_{\mathrm{cm}}$ [23].

From the experimentally obtained rock parameters, the mechanical parameters in the stope are calculated by equations (10) and (11); see Table 5 for details.

4.3. Model Establishment. The specific modeling process of the model is as follows: according to the geological conditions and size of the chamber, as shown in Figure 7, a 2D numerical model with a size of $150 \mathrm{~m}$ long and $54.43 \mathrm{~m}$ width is established. The mesh size of the model is $0.3 \sim 1.5 \mathrm{~m}$. The strainsoftening model based on the Hoek-Brown criterion is employed for coal rock mass. The horizontal displacement on around model is constrained, and the model bottom is constrained on the vertical displacement [24]. The model top is applied with a $12.5 \mathrm{MPa}$ vertical load [25].

4.4. Verification of the Numerical Simulation. To verify the rationality and accuracy of the constitutive model and mechanical parameters of the numerical model, a 
TABle 5: Mechanical parameters of the rock at Tashan Coal Mine.

\begin{tabular}{|c|c|c|c|c|c|c|}
\hline \multirow{2}{*}{ Lithology } & \multicolumn{2}{|c|}{ Intact rock } & \multirow{2}{*}{ RQD } & \multicolumn{3}{|c|}{ Rock mass } \\
\hline & $E(\mathrm{GPa})$ & $\sigma_{\mathrm{c}}(\mathrm{MPa})$ & & $E_{m}(\mathrm{GPa})$ & $\sigma_{\mathrm{cm}}(\mathrm{MPa})$ & $\sigma_{\mathrm{tm}}(\mathrm{MPa})$ \\
\hline Medium sandstone & 45.5 & 69.4 & 90 & 26.4 & 47.4 & 4.7 \\
\hline Sandstone & 36.2 & 23.6 & 89 & 20.1 & 15.7 & 1.6 \\
\hline Mudstone & 15.8 & 17.4 & 57 & 2.2 & 4.4 & 0.4 \\
\hline $3-5 \#$ coal seam & 6.8 & 13.2 & 65 & 1.4 & 4.2 & 0.4 \\
\hline Mudstone & 15.2 & 7.2 & 63 & 2.8 & 2.2 & 0.2 \\
\hline Coarse sandstone & 35.1 & 75.6 & 91 & 21.3 & 53.3 & 5.3 \\
\hline
\end{tabular}

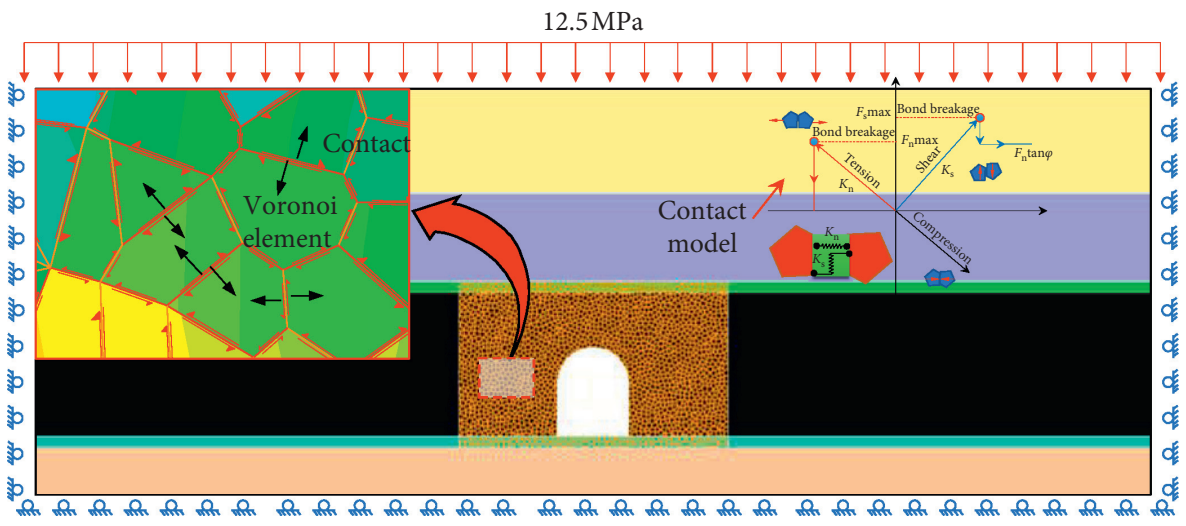

Figure 7: Numerical model.

verification study is performed by comparing the crack development characteristics and the surrounding rock deformation characteristics. As shown in Figure 7, the integrity of the rib at 2, 5 , and $10 \mathrm{~m}$ is obtained using the borehole television. From Figure 8, a large amount of damage is generated in the coal body at $2 \mathrm{~m}$, forming a fracture zone. At $5 \mathrm{~m}$, the coal body has many cracks, while at $10 \mathrm{~m}$, there are only a few cracks in the coal body. In this position, the numerical simulation of the fracture development is in good consistent with the observation results of the borehole television. Therefore, crack development characteristics verify the reliability of the simulation model.

As shown in Figure 9, a multipoint displacement meter is placed in the dome of the chamber to monitor the amount of roof separation and compare it with numerical simulation. From Figure 8, the numerical simulation results of the chamber roof separation are in good consistent with the field measurement results in terms of both value and trend. The chamber deformation verifies the reliability of the numerical simulation.

\section{Crack Development Characteristics of the Chamber and Its Relationship with Deformation}

After the excavation of the chamber, the chamber changes from the original triaxial stress state to the biaxial stress state, and even to a uniaxial stress state. Many cracks are produced in the chamber. The fractures initiate, expand, and eventually penetrate, which will inevitably destroy the integrity of the surrounding rock and reduce its resistance to deformation. This section studies the relationship between fracture development characteristics and deformation and reveals the mechanical mechanism of surrounding rock fracture development.

5.1. Relationship between Fracture Development Characteristics and Deformation. As shown in Figure 10, in order to reveal the relationship between the fracture development characteristics and the surrounding rock deformation, cracks in the both ribs and the lateral displacement of the ribs are separately extracted.

As shown in Figure 10(a), many cracks are produced in the chamber. In the range of $0 \sim 7.4 \mathrm{~m}$, the cracks penetrate each other. In the range of $7.4 \sim 12.7 \mathrm{~m}$, the cracks initiate and develop, while in the range of $12.7 \sim 20 \mathrm{~m}$, there are basically no cracks in the both ribs.

In this paper, the surrounding rock is divided into three areas, which are intact area, crack initiation and development area, and crack penetration area. The above three areas are mainly divided according to the development of cracks in the numerical simulation. The cracks penetrate each other in the fracture penetration area, while in the crack initiation and development area, although there are cracks, the cracks do not penetrate each other. And, there are no cracks in the intact area, as shown in Figure 11.

The following can be seen from Figure 10(b):

(1) At the range of $0 \sim 7.4 \mathrm{~m}$ ( $\mathrm{I}$ area), the lateral movement of the chamber coal rib is obvious. This zone is the crack penetration area of the ribs. The lateral 


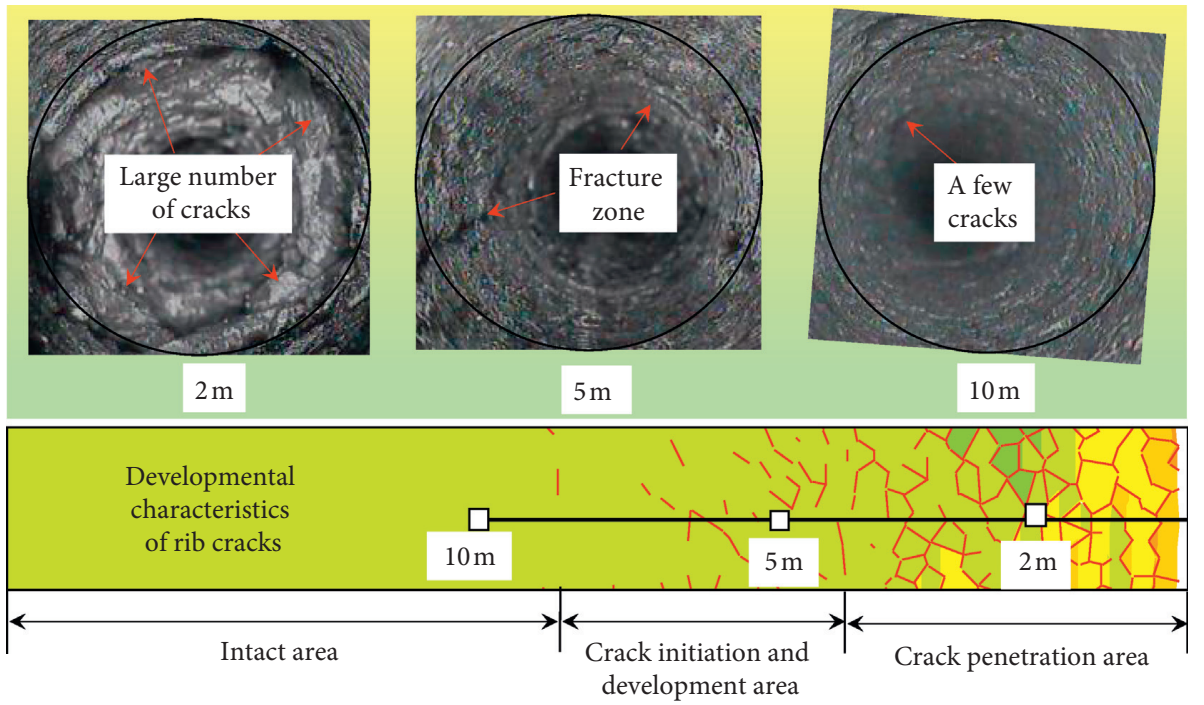

FIGURE 8: Comparison of crack development characteristics of chamber between numerical simulation and field measurement.



Figure 9: Comparison of the roof separation of numerical simulation and field measurement.

displacement is largest at the surface of the chamber ribs, the lateral displacement of which is $0.43 \mathrm{~m}$. In Figure 10(a), the closer to the surface of the chamber ribs, the larger the lateral displacement variation, which indicates the more serious damage and weaker bearing capacity. Under the effect of mine pressure, serious lateral displacement occurs in this penetration area.

(2) At the range of $7.4 \sim 12.7 \mathrm{~m}$ (II area), the variation of the lateral displacement in chamber ribs is significantly reduced. In Figure 10(a), this area is the initiation and development area of the rib cracks. No crack penetration occurs in this area, and therefore, the surrounding rock has certain bearing capability and the lateral displacement is significantly reduced.

(3) At the range of $12.7 \sim 20 \mathrm{~m}$ (III area), the lateral displacement of the chamber ribs is basically $0.05 \mathrm{~m}$.
In Figure 10(a), this area is the intact area of the ribs. The lateral displacement of the surrounding rock is caused by the surrounding rock movement.

According to the above rules, many cracks are produced in the chamber due to the effect of mining pressure. After the cracks penetrate each other, the chamber bearing capacity decreases sharply, which is manifested by a sharp increase in the displacement of the chamber in the crack penetration area. To reduce the occurrence of cracks and inhibit the penetration of cracks, it is necessary to further reveal the reason of crack development in the chamber.

5.2. Mechanism of Crack Development. According to the above laws, the deformation of surrounding rock is due to the crack development, and the deformation of chamber is 


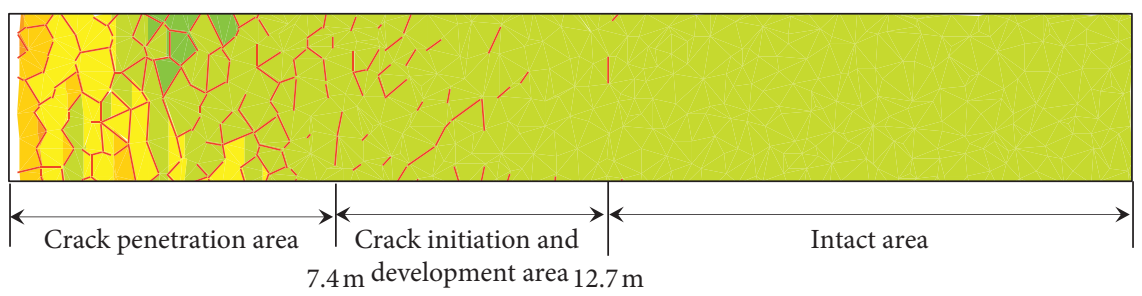

(a)

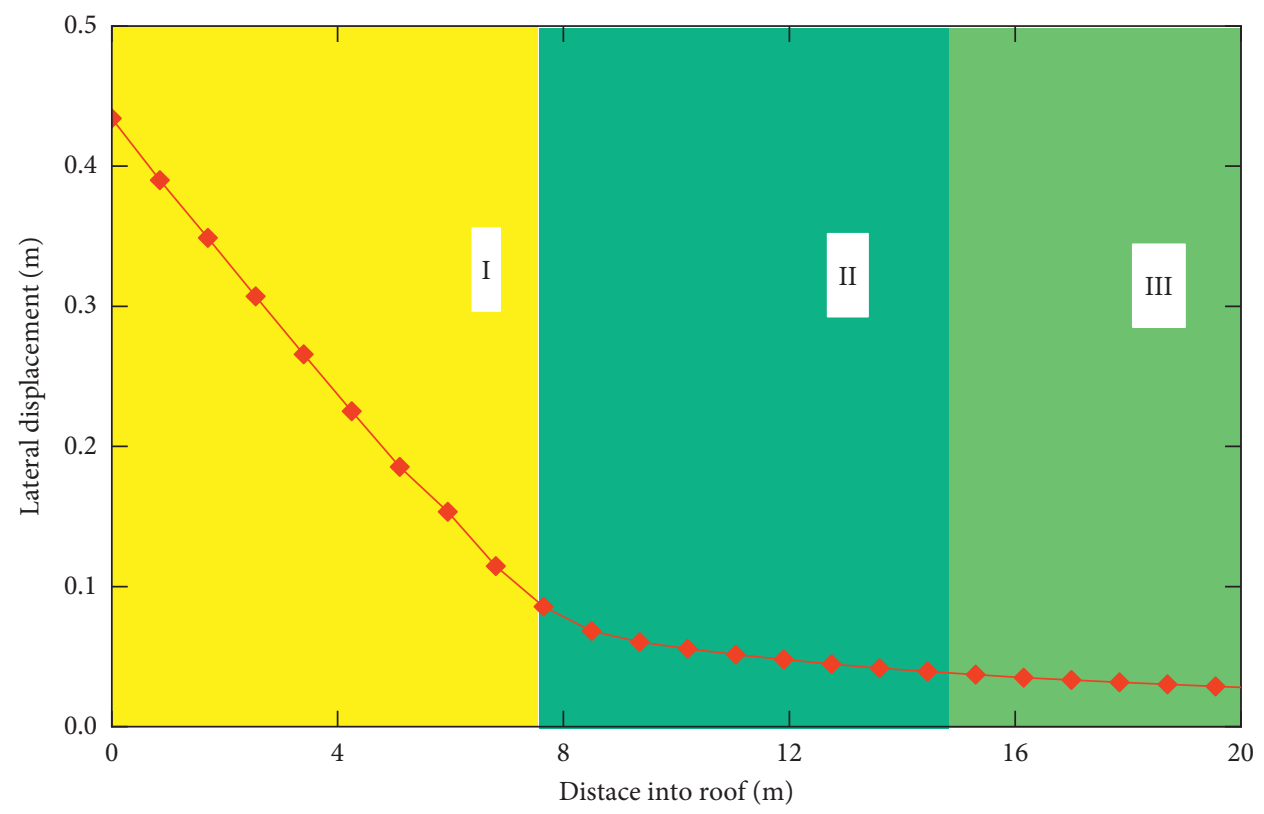

(b)

FIGURE 10: Relationship between crack development characteristics and deformation: (a) crack development characteristics and (b) deformation.

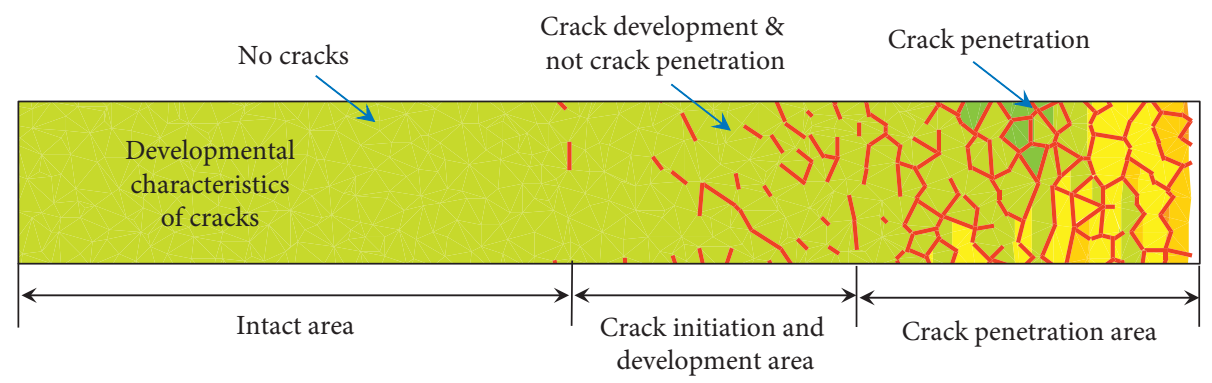

FIgURE 11: The division principle of the three areas.

large in the crack penetration zone. To reveal the reason of the crack development in the chamber, as shown in Figure 12 , the mechanism of crack generation is given.

As shown in Figure 12, due to mining pressure and mining disturbance, many cracks are generated in the chamber. The main mechanism for crack generation is due to the fact that shear stress in the chamber is over strength limit. As a result, shear failure occurs. Compared with shear failure, tensile failure is relatively less. The percentage of cracks from shear failure and tensile failure of the chamber are $98.2 \%$ and $19.3 \%$, respectively. Therefore, the shear failure zone of the chamber occurs substantially simultaneously with the tensile failure. The shear failure causes the friction angle and cohesive force of the chamber to decrease sharply and the tensile strength also drops. Therefore, the shear failure zone also undergoes tensile failure at the same time.

\section{Control of the Chamber in Extra-Thick Coal Seam}

From the relationship between crack development characteristics and deformation of the chamber and the mechanism of the crack development, it is gotten that increasing 


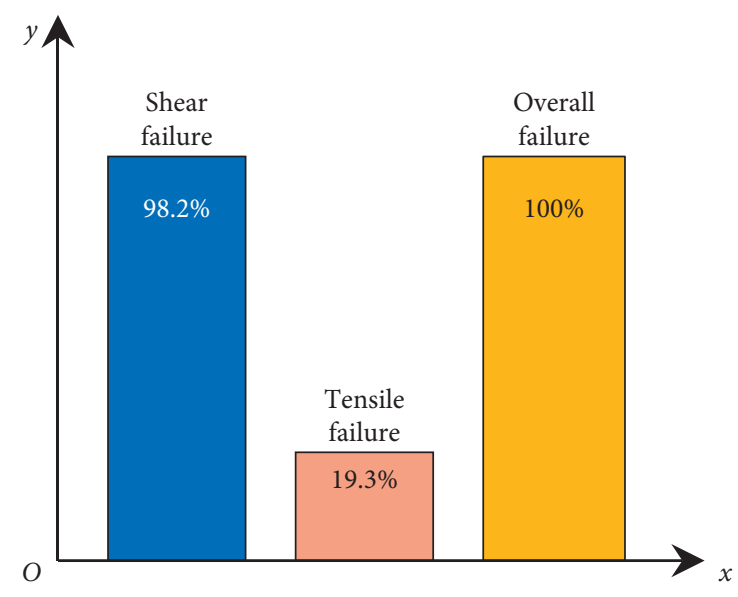

Figure 12: Crack model in the chamber.

the shear strength limit of the chamber and reducing the crack penetration is an effective method to control the chamber deformation.

\subsection{Basic Principle of Surrounding Rock Control}

6.1.1. Grouting Reinforcement. After the excavation of the chamber, cracks are initiated in the chamber. Due to the mine pressure, the cracks continue to expand and eventually penetrate. The grouting technology injects the slurry into the cracks of the coal rock mass, making it a new structure with high strength and high stability, thus achieving a good support effect. At present, the grouting method commonly used in coal mines is the pressure injection method. In this method, the chemical slurry is injected into the coal rock mass by a pressure injection pump and the loose coal rock mass is connected into an organic whole.

From the analysis of coal rock body failure mechanism and mechanical principle, the main effects of slurry on coal rock mass can be summarized as network skeleton effect, bond reinforcement effect, filling compaction effect, and failure transformation mechanism [26].

(1) Network skeleton effect. During the reinforcement construction process, the slurry penetrates into cracks of the coal rock mass. After reacted and consolidated, a new network skeleton structure is formed in the coal rock body. When the external load exceeds the rock strength limit, it will be destroyed and deformed greatly. Then, the reinforcement material network will play a skeleton role with its good toughness and bond strength performance, thereby improving the shear strength limit of the rock [27].

(2) Bond reinforcement effect. The cohesion and tensile strength on the crack of coal rock mass are almost zero. After reinforcement, the reinforcement material can bond the fractured coal rock mass, which is already in a plastic state, maintaining its cohesive force and friction angle [28]. The shear strength limit of rock can be improved, according to the Mohr-Coulomb criterion.
(3) Filling compaction effect. Under the influence of the pumping pressure and the expansion pressure formed by the self-reaction, the slurry can fill the gaps of the interconnected coal rock mass and can also fill and compact the coal rock mass as a whole. This effect can significantly increase the shear strength of coal rock mass.

(4) Failure transformation mechanism. When there is a crack in a continuous medium, a strong stress concentration is formed during the load-bearing process with the maximum stress being concentrated at the tip of the crack. After reinforcement, the crack is filled with reinforcing material, and the bonding effect of the material on the crack will greatly weaken or eliminate the stress concentration at the crack tip, thereby avoiding rock shear failure [29].

The above-mentioned effects of the slurry increase the shear strength of the rock and reduce the occurrence of shear failure.

6.1.2. High Prestressed Anchor. Long anchor cable or lengthened anchor bolt can provide axial and shear forces simultaneously. First, the force of the surrounding rock is changed by the axial force, and the anchor is transformed from the biaxial stress state to the triaxial stress state. Second, through the transverse connection with the anchor, the shear stress and bending distance are born [30]. The anchor bolt can improve the rock cohesive force. The specific formula is as follows:

$$
c=c_{0}+n c_{m},
$$

where $c$ and $\varphi$ are the cohesive force and friction angle before the anchor failure, respectively. $c_{0}(\mathrm{MPa})$ is the rock cohesion without the anchor bolt. $n$ is the number of anchor arrangements in the anchor body. $c_{\mathrm{m}}(\mathrm{MPa})$ is the additional cohesion provided by a single anchor and is expressed as

$$
c_{m}=\frac{F_{b \max }}{s \cos }\left(\frac{45^{\circ}-\varphi}{2}\right) \text {. }
$$

In the above equation, $F_{\mathrm{bmax}}$ is the maximum shear force that the bolt can withstand under pure shear conditions. Its expression is as follows:

$$
F_{b \max }=\frac{\pi \sigma_{s} d^{2}}{4 \sqrt{3}},
$$

where $\sigma_{s}$ is the bolt yield strength, MPa; $d$ is the bolt diameter, $m$; and $s$ is the free area of the test body, $\mathrm{m}^{2}$.

$$
c_{m}=c_{0}+\frac{\pi n \sigma_{s} d^{2}}{4 \sqrt{3} s \cos \left(\left(45^{\circ}-\varphi\right) / 2\right)} .
$$

In addition, the anchor can also improve the friction angle of the surrounding rock $\varphi$ [31]. According to the Mohr-Coulomb strength criterion, the shear strength limit of the rock can be increased to some extent.

The anchor cable can provide a high pretightening force (PTF) to reinforce the chamber, which effectively connects 
the broken surrounding rock together to form a unified composite and thus significantly improves the shear strength of the crack $[32,33]$.

6.2. Control Technology of Surrounding Rock. Based on theoretical analysis, after the anchor support and grouting reinforcement, the shear strength limit of the chamber can be improved. However, the method for determining the anchor parameters and grouting parameters is not yet given. The anchor parameters and grouting parameters will be optimized in this section based on the crack development characteristics by means of numerical simulation.

6.2.1. Anchor Support. The support parameters of the anchor include spacing, length, PTF, etc. According to the theoretical analysis, the anchor can improve the shear strength limit of the rock, inhibit and reduce the surrounding rock shear failure, and decrease the possibility of the cracks interpenetrating. Based on this theory and taking the PTF of the bolt as an example, the method of determining the pretightening force is given. As shown in Figure 13, the crack expansion characteristics of the chamber ribs are given when the PTF of the bolt is $25,50,100$, and $125 \mathrm{kN}$.

The following can be seen from Figure 13:

(1) When the PTF of the anchor bolt is $25 \mathrm{kN}$, the surrounding rock of the chamber ribs forms a crack penetration area, a crack initiation and development area, and an intact area. The range of the crack penetration area is $0 \sim 6.7 \mathrm{~m}$. In this area, the surrounding rock is seriously damaged, resulting in a drastically decreased bearing capacity and serious deformation.

(2) When the PTF of the anchor bolt is $50 \mathrm{kN}$, the crack expansion of the chamber ribs is similar to that at $25 \mathrm{kN}$, but the crack penetration area is significantly reduced.

(3) When the PTF of the anchor bolt is $100 \mathrm{kN}$, the surrounding rock of the chamber ribs forms a crack initiation and development area and an intact area, but there is no crack penetration area. The chamber ribs have a certain load-bearing capacity, and thus the deformation and damage are well controlled.

(4) When the PTF of the anchor bolt is $125 \mathrm{kN}$, the chamber ribs also only have crack initiation and development area and intact area. Moreover, the crack initiation and development area are reduced, while the intact area is increased, indicating that the deformation and damage of the chamber are well controlled.

From the above result, when the PTF is $100 \mathrm{kN}$, the surrounding rock of the chamber ribs only has a crack initiation and development area and an intact area, and the surrounding rock deformation is well controlled. Therefore, the PTF of the anchor bolt is determined to be $100 \mathrm{kN}$. Other parameters of the anchor are determined by optimization methods similar to that of the anchor bolt PTF. The final support parameters are determined: the spacing of anchor bolts is $900 \mathrm{~mm} \times 900 \mathrm{~mm}$, the PTF is $100 \mathrm{kN}$, the length of the dome anchor bolt is $2500 \mathrm{~mm}$, and the anchor bolt length at two ribs is $1800 \mathrm{~mm}$. The spacing of anchor cables is $2700 \times 1800 \mathrm{~mm}$, the PTF is $150 \mathrm{kN}$, and the length is $8300 \mathrm{~mm}$.

6.2.2. Grouting Reinforcement. In the grouting reinforcement, the spacing of the grouting pipe and the grouting pressure are the core parameters. The grouting spacing is determined by the diffusion radius of the slurry, which mainly depends on the grouting pressure, the degree of crack development, the rock properties, etc., and the flow dynamics parameters of the slurry. The diffusion radius is closely related to the grouting pressure under certain surrounding rock conditions and grouting materials. A numerical simulation is built, and the relationship of the diffusion range and grouting pressures is obtained. From the simulation, while the grouting pressure reaches $5.0 \mathrm{MPa}$, the slurry diffusion radius is basically stable at $1800 \mathrm{~mm}$. Therefore, the anchor bolt spacing is $900 \mathrm{~mm}$, and the grouting pressure is $5 \mathrm{MPa}$.

6.3. Fracture Control Effect. From the above analysis, it is found that reasonable grouting and anchor support parameters can inhibit the penetration of cracks and control the deformation of the chamber. As shown in Figure 14, the crack development characteristics in the chamber under the combined effect of these two supporting methods are further analyzed. Then, the surrounding rock control effect is evaluated.

The following can be drawn from Figure 14:

(1) By combined support, there are only a few cracks in the chamber dome, while cracks are relatively more on the dome sides. However, in general, the fractures significantly decrease and there is no crack penetration zone. Therefore, the cracks in the chamber dome are well controlled.

(2) By combined support, there are a few cracks in the chamber ribs, but the cracks do not penetrate each other.

Based on the above analysis, after the combined support of grouting and high-strength anchor, the cracks in the chamber only have crack initiation and development area and intact area. According to the relationship between the crack development characteristics and deformation of the chamber, it can be drawn that the chamber deformation can be well controlled.

\section{Engineering Application}

7.1. Support Scheme. From the above laws, grouting equipment with a grouting pressure of $5.0 \mathrm{MPa}$ is placed every two anchor bolts. The anchor support is applied after grouting, as shown in Figure 15. Specific supporting parameters are given in Section 6.

7.2. Chamber Deformation Measurement. As shown in Figure 16, deformation at different chamber depths are monitored by the multipoint displacement meters. They are put at depths of 2, 4, 6, 8, and $10 \mathrm{~m}$. 

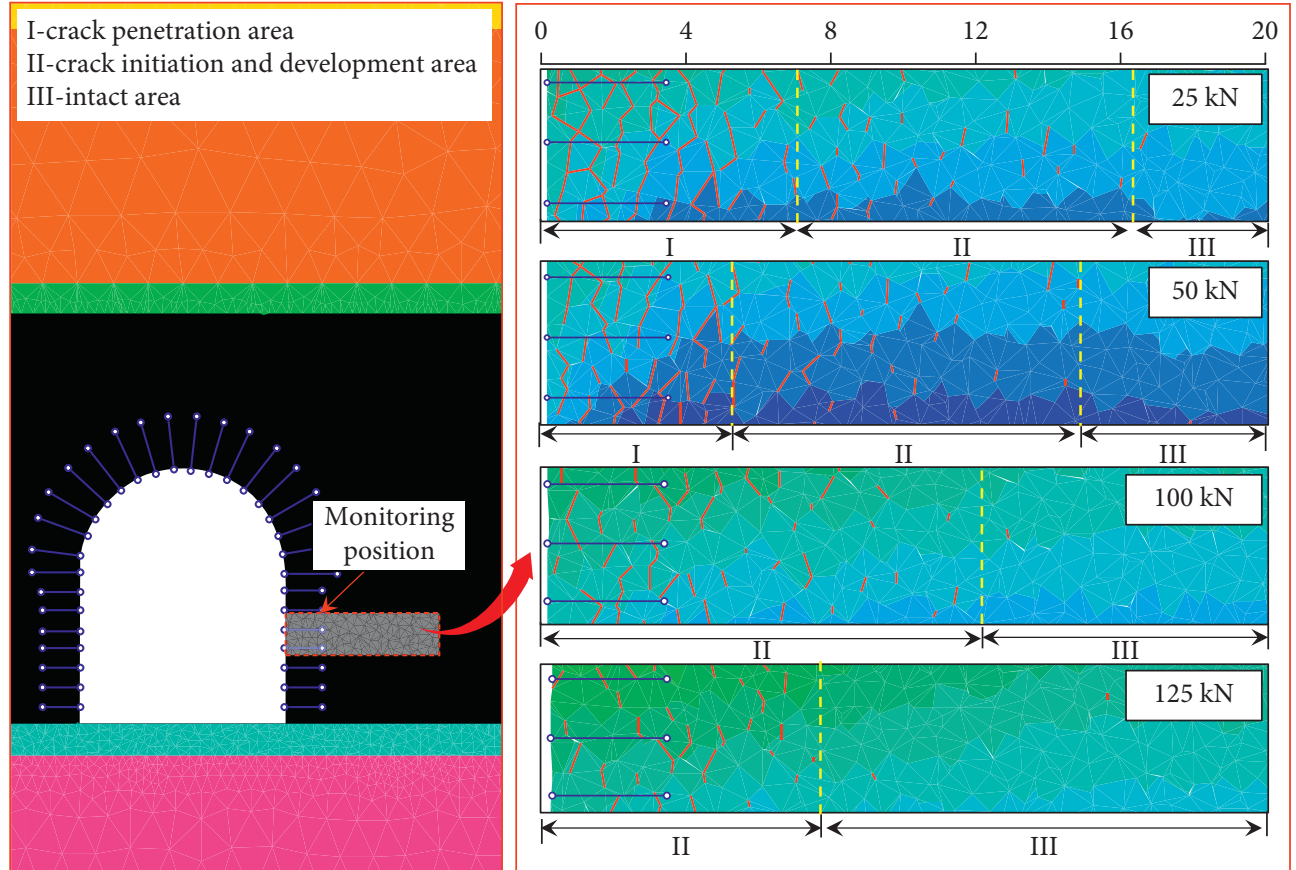

Figure 13: Optimization for the PTF for anchor bolt.

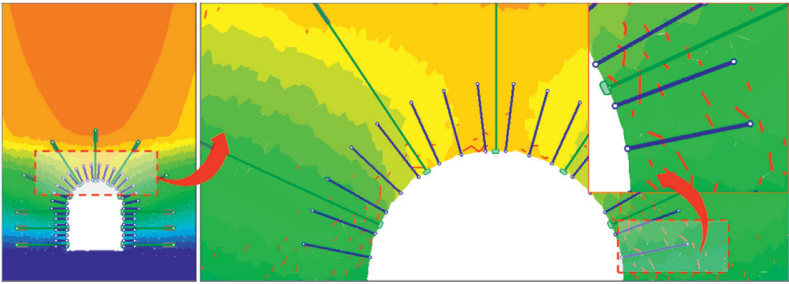

(a)

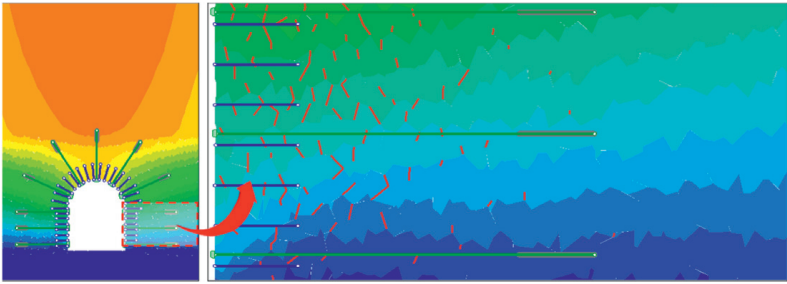

(b)

FIGURE 14: The crack development characteristics of surrounding rock: (a) cracks in the dome and (b) cracks in the ribs.

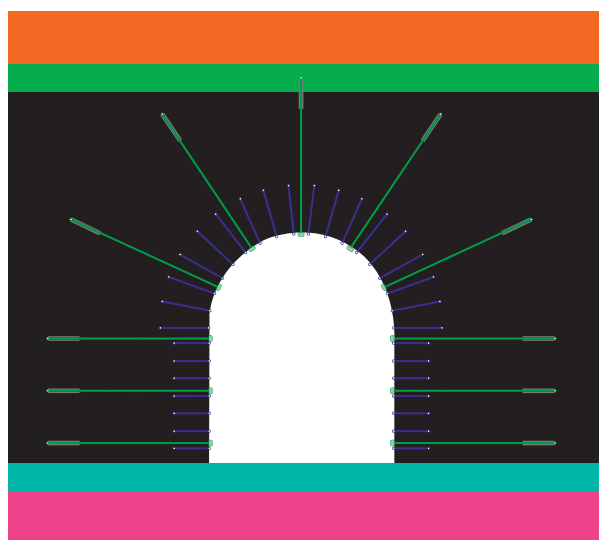

FIGURE 15: Chamber support scheme. 


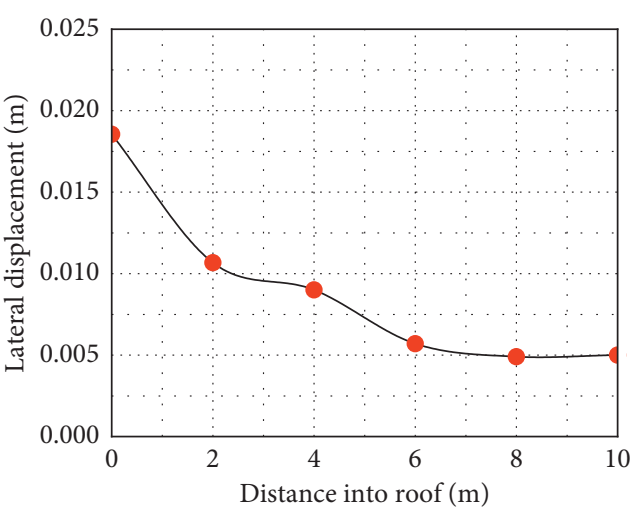

(a)

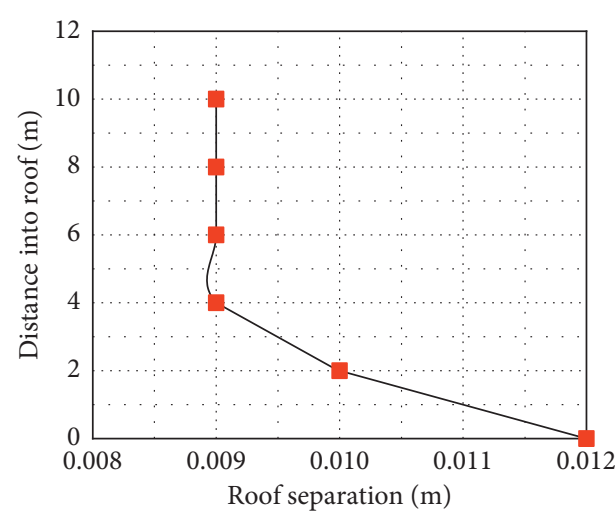

(b)

FIGURE 16: Chamber deformation: (a) lateral displacement and (b) roof separation.

It can be seen from Figure 16(a) that the maximum value of lateral displacement is $18 \mathrm{~mm}$ and the area is the crack initiation and development area. The lateral displacement of the surrounding rock beyond $6 \mathrm{~m}$ is basically kept at $6 \mathrm{~mm}$, and the area is the intact area.

It can be seen from Figure 16(b) that the maximum value of roof separation is $12 \mathrm{~mm}$ and the area is the crack initiation and development area. The roof separation beyond $4 \mathrm{~m}$ is basically kept at $9 \mathrm{~mm}$, and the area is the intact area.

From the above laws, the chamber deformation is well controlled.

\section{Conclusion}

After the introduction of geological conditions of the chamber, this paper reveals the relationship between the crack development characteristics and deformation of surrounding rock, as well as the mechanical mechanism of crack generation based on numerical simulation analysis. The following results can be drawn:

(1) The drawbacks of the loosened ring theory, reinforcement arch theory, and prestressed support theory are analyzed. The control theory of surrounding rock in a large-section chamber of extra-thick coal seam based on chamber crack development characteristics is proposed.

(2) After driving the chamber, much shear damage is generated in the chamber ribs due to the effect of the mine pressure and excavation disturbance, resulting in the formation of many cracks. These cracks further extend and expand. When the crack penetrates, the bearing capacity of the chamber ribs decreases sharply and the deformation of the surrounding rock increases significantly.

(3) From crack development characteristics and the surrounding rock deformation, as well as the mechanism of crack generation, the support technology combining high-strength anchor with the grouting reinforcement is proposed. By optimizing the above supporting and grouting parameters, the generation of cracks in the chamber is controlled, and crack penetration is suppressed. Finally, an industrial test was conducted in the chamber at Datong Coal Group, which showed that chamber deformation and failure were well controlled.

\section{Data Availability}

Part of the data used to support the findings of this study are included within the article, and the rest of the data used to support the findings of this study are available from the corresponding author upon request.

\section{Conflicts of Interest}

The authors declare no conflicts of interest.

\section{Acknowledgments}

This work was funded by the State Key Research Development Program of China (2018YFC0604500) and LiaoNing Revitalization Talents Program (XLYC1807219). The authors gratefully acknowledge the financial support from the organization.

\section{References}

[1] Y. M. Cheng, J. A. Wang, G. X. Xie, and W. B. Wei, "Threedimensional analysis of coal barrier pillars in tailgate area adjacent to the fully mechanized top caving mining face," International Journal of Rock Mechanics and Mining Sciences, vol. 47, no. 8, pp. 1372-1383, 2010.

[2] B. Yu, J. Zhao, T. Kuang, and X. Meng, "In situ investigations into overburden failures of a super-thick coal seam for longwall top coal caving," International Journal of Rock Mechanics and Mining Sciences, vol. 78, pp. 155-162, 2015.

[3] N. E. Yasitli and B. Unver, "3D numerical modeling of longwall mining with top-coal caving," International Journal of Rock Mechanics and Mining Sciences, vol. 42, no. 2, pp. 219-235, 2005.

[4] B. Yu, R. Zhang, M.-Z. Gao, G. Li, Z.-T. Zhang, and Q.-Y. Liu, "Numerical approach to the top coal caving process under different coal seam thicknesses," Thermal Science, vol. 19, no. 4, pp. 1423-1428, 2015. 
[5] W. P. Huang, Q. Yuan, Y. L. Tan et al., "An innovative support technology employing a concrete-filled steel tubular structure for a 1000-m-deep roadway in a high in situ stress field," Tunnelling and Underground Space Technology, vol. 73, pp. 26-36, 2018.

[6] H. A. Lazemi, M. Fatehi Marji, A. R. Yarahmadi Bafghi, and K. Goshtasbi, "Rock failure analysis of the broken zone around a circular opening/analiza pęknięcia skały w strefie naruszonej wokół otworu kolistego," Archives of Mining Sciences, vol. 58, no. 1, pp. 165-188, 2013.

[7] P. A. Martynyuk and E. N. Sher, "Effect of free surface on the shape of a zone broken in blasting of a cord charge in a rock mass," Journal of Mining Science, vol. 34, no. 5, pp. 438-447, 1998.

[8] Q. Wang, R. Pan, B. Jiang et al., "Study on failure mechanism of roadway with soft rock in deep coal mine and confined concrete support system," Engineering Failure Analysis, vol. 81, pp. 155-177, 2017.

[9] T. Hong sheng, T. Shi hao, W. Chen, H. Ding yi, and Z. De fu, "Mechanical analysis of a vertical-wall, semicircular-arch roadway and a repair technique using double-shell support," Environmental Earth Sciences, vol. 77, no. 13, 2018.

[10] X. Sun, B. Zhang, L. Gan, Z. Tao, and C. Zhao, "Application of constant resistance and large deformation anchor cable in soft rock highway tunnel," Advances in Civil Engineering, vol. 2019, Article ID 4347302, 19 pages, 2019.

[11] W. Yu and F. Liu, "Stability of close chambers surrounding rock in deep and comprehensive control technology," $A d$ vances in Civil Engineering, vol. 2018, Article ID 6275941, 18 pages, 2018.

[12] W. Yu, B. Pan, F. Zhang, S. Yao, and F. Liu, "Deformation characteristics and determination of optimum supporting time of alteration rock mass in deep mine," KSCE Journal of Civil Engineering, vol. 23, no. 11, pp. 4921-4932, 2019.

[13] W. Fan, M.-h. Yu, L.-s. Deng, X. Peng, and L.-w. Chen, "New strength formulae for rock surrounding a circular opening," Canadian Geotechnical Journal, vol. 50, no. 7, pp. 735-743, 2013.

[14] M. Cai, P. K. Kaiser, Y. Tasaka, and M. Minami, "Determination of residual strength parameters of jointed rock masses using the GSI system," International Journal of Rock Mechanics and Mining Sciences, vol. 44, no. 2, pp. 247-265, 2007.

[15] E. Hoek and C. D. Martin, "Fracture initiation and propagation in intact rock-a review," Journal of Rock Mechanics and Geotechnical Engineering, vol. 6, no. 4, pp. 287-300, 2014.

[16] E. Eberhardt, "The Hoek-Brown failure criterion," Rock Mechanics and Rock Engineering, vol. 45, no. 6, pp. 981-988, 2012.

[17] R. Gao, H. Xia, K. Fang, and C. Zhang, "Dome roof fall geohazards of full-seam chamber with ultra-large section in coal mine," Applied Sciences, vol. 9, no. 18, 2019.

[18] Q.-S. Bai, S.-H. Tu, C. Zhang, and D. Zhu, "Discrete element modeling of progressive failure in a wide coal roadway from water-rich roofs," International Journal of Coal Geology, vol. 167, no. 10, pp. 215-229, 2016.

[19] F. Gao, D. Stead, and H. Kang, "Numerical simulation of squeezing failure in a coal mine roadway due to mining-induced stresses," Rock Mechanics and Rock Engineering, vol. 48, no. 4, pp. 1635-1645, 2014.

[20] Q.-S. Bai, S.-H. Tu, M. Chen, and C. Zhang, "Numerical modeling of coal wall spall in a longwall face," International Journal of Rock Mechanics and Mining Sciences, vol. 88, no. 8, pp. 242-253, 2016.
[21] M. Shabanimashcool and C. C. Li, "Numerical modelling of longwall mining and stability analysis of the gates in a coal mine," International Journal of Rock Mechanics and Mining Sciences, vol. 51, no. 4, pp. 24-34, 2012.

[22] M.-h. Ju, X.-h. Li, Q.-1. Yao, D.-w. Li, Z.-h. Chong, and J. Zhou, "Numerical investigation into effect of rear barrier pillar on stress distribution around a longwall face," Journal of Central South University, vol. 22, no. 11, pp. 4372-4384, 2015.

[23] X. Yang, E. Wang, Y. Wang, Y. Gao, and P. Wang, "A study of the large deformation mechanism and control techniques for deep soft rock roadways," Sustainability, vol. 10, no. 4, p. 1100, 2018.

[24] X. Li, M. Ju, Q. Yao, J. Zhou, and Z. Chong, "Numerical investigation of the effect of the location of critical rock block fracture on crack evolution in a gob-side filling wall," Rock Mechanics and Rock Engineering, vol. 49, no. 3, pp. 1041-1058, 2015.

[25] G. S. P. Singh and U. K. Singh, "Numerical modeling study of the effect of some critical parameters on caving behavior of strata and support performance in a longwall working," Rock Mechanics and Rock Engineering, vol. 43, no. 4, pp. 475-489, 2009.

[26] S. Ma, Z. Zhao, W. Nie, and X. Zhu, "An analytical model for fully grouted rockbolts with consideration of the pre- and post-yielding behavior," Rock Mechanics and Rock Engineering, vol. 50, no. 11, pp. 3019-3028, 2017.

[27] X. Zhai, G. Huang, C. Chen, and R. Li, "Combined supporting technology with bolt-grouting and floor pressure-relief for deep chamber: an underground coal mine case study," Energies, vol. 11, no. 1, p. 67, 2018.

[28] Z.-Q. Kang, Q. Han, S.-Q. Zhang, N. Li, and Anonymous, "Study on numerical simulation and bolt grouting mechanism of mine fracture rock masses," in Proceedings of the 2nd International Conference on Electronic and Mechanical Engineering and Information Technology, Paris, France, September 2014.

[29] M. H. Salimian, A. Baghbanan, H. Hashemolhosseini, M. Dehghanipoodeh, and S. Norouzi, "Effect of grouting on shear behavior of rock joint," International Journal of Rock Mechanics and Mining Sciences, vol. 98, no. 7, pp. 159-166, 2017.

[30] C. H. Liu and Y. Z. Li, "Analytical study of the mechanical behavior of fully grouted bolts in bedding rock slopes," Rock Mechanics and Rock Engineering, vol. 50, no. 9, pp. 2413-2423, 2017.

[31] H. Kang, J. Li, J. Yang, and F. Gao, "Investigation on the influence of abutment pressure on the stability of rock bolt reinforced roof strata through physical and numerical modeling," Rock Mechanics and Rock Engineering, vol. 50, no. 2, pp. 387-401, 2016.

[32] B. Jiang, Q. Wang, S. C. Li et al., "The research of design method for anchor cables applied to cavern roof in water-rich strata based on upper-bound theory," Tunnelling and Underground Space Technology, vol. 53, pp. 120-127, 2016.

[33] H. Yan, F.-1. He, L.-y. Li, R.-m. Feng, and P.-f. Xing, "Control mechanism of a cable truss system for stability of roadways within thick coal seams," Journal of Central South University, vol. 24, no. 5, pp. 1098-1110, 2017. 